\title{
What's now, what's new and what's next in virgin olive oil elaboration systems? A perspective on current knowledge and future trends
}

\author{
Maria Lisa Clodoveo, ${ }^{1}$ Tiziana Dipalmo, ${ }^{1}$ Cristina Schiano, ${ }^{1}$ Domenico La Notte, ${ }^{1}$ \\ Sandra Pati ${ }^{2}$ \\ ${ }^{1}$ Department of Agricultural and Environmental Science, University of Bari; ${ }^{2}$ Department of the \\ Sciences of Agriculture, Food and Environment, University of Foggia, Italy
}

\begin{abstract}
The aim of virgin olive oil elaboration process is to obtain the highest recovery of the best quality oil from the fruits. The aim of the researchers is to understand the key elements that allow to modulate the complex series of physical, physico-chemical, chemical and biochemical transformations in order to develop innovative and sustainable plant solutions able to increase simultaneously both yield and quality of product. The basic principles applied also in the newest olive oil industrial plants still follow the technical knowledge which have been empirically learned by humans thousands of years ago. In fact, it is well known that three factors, mixing, water adding and warming, are the three macroscopic driving forces able to favour the separation of the oily phase from the mass of crushed olives.

In this consolidated scenario, can new elements emerge? The whole process should be considered more than a simple extraction of the oil present in fruit cells, but a complex elaboration of a product, which is depleted and enriched of both constitutive and neo-synthesised compounds through complex phenomena only in part discovered. In fact, while it is evident that numerous studies have been conducted to elucidate the behaviour of olive paste during virgin olive oil extraction process, a key conclusion is that the current level of understanding can be improved further by means the development of more rigorous researches with more focused targets aimed to understand the rheological changes, the coalescence phenomena, the changes in hydrophobic and hydrophilic phenomena, the partition equilibrium of
\end{abstract}

Correspondence: Maria Lisa Clodoveo, Department of Agricultural and Environmental Science, University of Bari, via Amendola 165/a, 70126 Bari, Italy.

Tel.: +39.080.5442514 - Fax: +39.080 .5442504 - Mobile: +39.334 .605 .3 .605 .

E-mail: marialisa.clodoveo@uniba.it

Key words: virgin olive oil elaboration process, hydrophobic effects, coalescence, partition phenomena, emerging technologies.

Received for publication: 14 June 2013.

Accepted for publication: 7 April 2014.

(C) Copyright M.L. Clodoveo et al., 2014

Licensee PAGEPress, Italy

Journal of Agricultural Engineering 2014; XLV:193

doi:10.4081/jae.2014.193

This article is distributed under the terms of the Creative Commons Attribution Noncommercial License (by-nc 3.0) which permits any noncommercial use, distribution, and reproduction in any medium, provided the original author(s) and source are credited. minor compounds between aqueous and oily phases and, last but not least, the favourable and unfavourable enzymatic reactions.

This paper provides an analysis of the present research field and its strengths and weaknesses are discussed. Potentially important future directions for research are also proposed.

\section{Introduction}

Italian equipment manufacturing industry for the extraction of the virgin olive oil is an important sector, which has historically focused its efforts on producing crushing machineries, sophisticated malaxing machines and centrifugal equipment (Amirante et al., 2010b). However, in the last decade, the Italian olive oil industry, despite performing well at extra virgin olive oil competitions, has been found itself in a financial predicament driven by stagnant market prices and rising production costs, among other factors. This predicament has been also reflected in the plant engineering industry characterised by a reduced performance, mainly in the last five years. Many efforts should be made in order to break out of the crisis, mainly through process innovation and new product development aimed to sustain the producers' income and, as consequence, to revitalise the market of equipment and plants for virgin olive oil elaboration (Clodoveo et al., 2014). The technological innovation is the driving force of a healthy growth, a rapid development of any enterprise, and the development of good business. The development of innovations able to impact the market is the main tool to improve the performance of an industrial sector. This step is fundamental for the virgin olive oil sector also considering that, despite the plethora of scientific researches aimed to increase the quality of virgin olive oil and the efficiency of the extraction plants, the industrial process has changed very little over the last 20 years (Clodoveo, 2013a, 2013b). The introduction of the horizontal centrifuge (decanter), coupled with the malaxation machine, has been the last big revolution in the virgin olive oil technology field (Amirante et al., 2000; Clodoveo, 2013b). Innovation have to start with a comprehensive analysis of the existing knowledge essential to get answers to the questions unanswered until now: this is the main goal of this paper, which presents an overview and a thematic analysis of publications on the relation between mechanical equipment, virgin olive oil quality and yield. It also reviews the directions of research that have been considered important to highlight the future trends of the plant engineering industry in this food sector.

\section{Background}

Modern olive mill plants are defined continuous and, generally, are 
constituted by a mechanical crusher, one or more malaxers, and a horizontal-axis centrifugal separator (decanter) (Amirante et al., 2000; Clodoveo, 2013b). The designation continuous relates to the fact that two of the three machines composing the system operate continuously (crusher and decanter), the malaxer, which actually is a machine operating in batches, is placed between these two continuous apparatuses (Clodoveo, 2012).

It is interesting to note that after more than 50 years of research on this topic and despite the relevant number of different prototypes developed so far, none of the currently available malaxer machine is able to work in continuous. The malaxation actually represents the weakest link of the chain in the virgin olive oil elaboration process (Figure 1); in fact, the malaxer, being a batch plant, represents the bottleneck of the continuous extraction process.

Currently the system used to guarantee continuity to the process, without interrupting the activity of the machines upstream (crusher) and downstream (decanter) of the malaxer, consists in placing several malaxing machines in parallel, with the burden of a heavy economic investment (Clodoveo, 2013a, 2013b) (Figure 2).

\section{Evolution of malaxing machines}

Figure 3 summarises the evolution of the malaxer machine along the last 15 years. The early malaxers had a cradle shape (Figure $3 \mathrm{~A}$ ) and a non-hermetic closure consisting in a stainless steel grill (Figure 3B). Later, the malaxation has been conducted under sealed conditions (Figure $3 \mathrm{C}$ ) in order to reduce the oxidation phenomena and the escape of volatile compounds. The subsequent step was the introduction of inert gas to modulate the oxygen concentration in the headspace of the tank (Figure 3D). In order to optimise the heat exchange a new model was specifically designed with a cylindrical jacket that covers the whole internal surface of the tank (Figure 3E). The hermetic sealing ensures a perfect control of the atmosphere in contact with the paste in the malaxing machine through valves for inert gas treating (nitrogen or argon). In the reality, the malaxation under inert gas is not widely widespread due to the high cost of nitrogen and argon that cannot be ignored (Clodoveo, 2013a). In fact, in order to address this problem, Parenti et al. (2006) suggested to profit by the phenomenon of $\mathrm{CO}_{2}$ emission coupled with the $\mathrm{O}_{2}$ depletion during malaxation under sealed conditions. The last evolution is represented by malaxer equipped with sensors, which are able to measure the temperature of the olive paste and the oxygen concentration in the headspace and inside the olive paste (Amirante et al., 2008; Amirante et al., 2012a). Despite the great economic and intellectual efforts, this research activity doesn't resolve the main question that compromises the whole efficiency of the actual continuous extraction system: the conversion of malaxation from batch to continuous process (Clodoveo, 2013b).

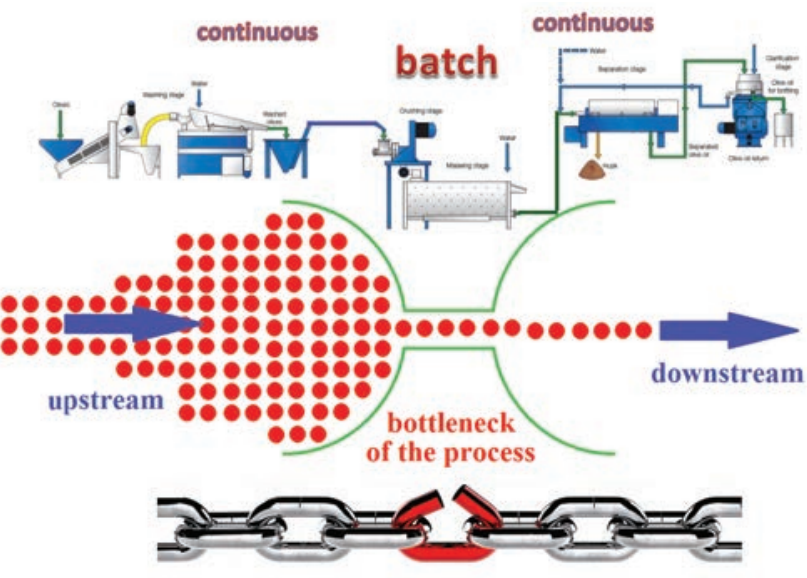

Figure 1. Malaxation represents the bottleneck of the continuous extraction process.

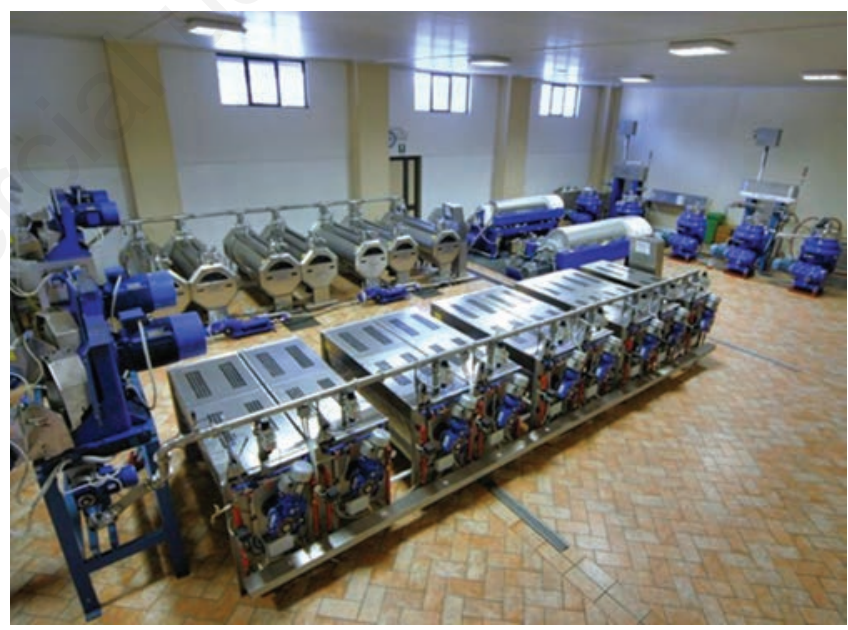

Figure 2. Virgin olive oil extraction plant equipped with plural malaxing machines in parallel (Courtesy of Alfa Laval Olive Oil S.p.A.).

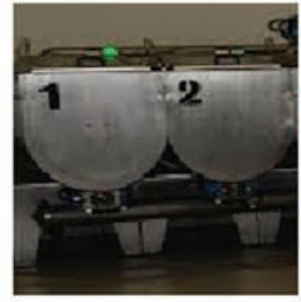

A

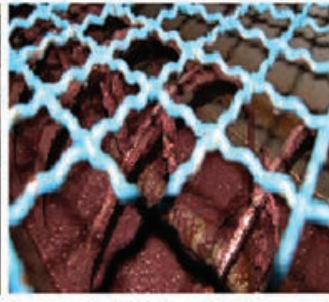

B

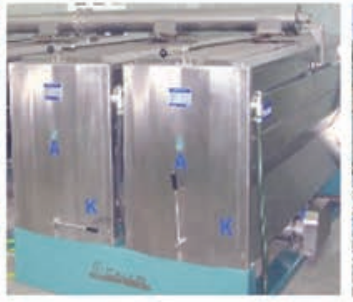

C

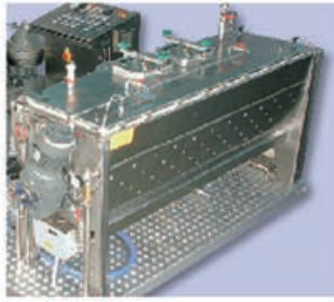

D

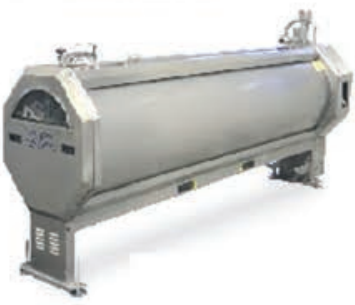

$\mathbf{E}$

Figure 3. Evolution of malaxing machines. 


\section{Need for speed in innovation}

Why does this kind of innovations develop so slowly if, in contrast, the industrial food sector is characterised by a high speed of progress?

The basic principles applied in the newest olive oil industrial plants follow the knowledge which have been empirically learned by humans thousands of years ago, probably already in the Neolithic age. In fact, it is well known that three factors, mixing, water adding and warming, are the macroscopic driving forces able to bring to the surface the oil from the mass of crushed olives (Clodoveo, 2012). It is also a sign that a deep revolution in the virgin olive oil process has not yet occurred, but it is necessary to achieve a real innovation that could raise, even financially, the sector of the olive oil production. However, the main obstacle of progress is the belief that much is already known about the phenomena that occur inside the olive paste during the virgin olive oil elaboration process. It is necessary, in contrast, to emphasise how still little are the knowledge and the scientific evidences on the mechanical, physical, physico-chemical, chemical and biochemical transformations that occurs during malaxation.

In a recent paper Clodoveo (2012) extensively examined with a critical analysis the effects of macroscopic malaxing parameters, such as time, temperature and atmosphere in contact with the olive paste, on the microscopic changes inside the olive paste, such as rheological changes, partition phenomena of polar compounds between oil and vegetation water, coalescence of oil droplets, chemical and biochemical oxidative reactions, desirable and undesirable enzymatic activities. From the analysis the great quantity of literature dedicated to the effect of the malaxing conditions on the virgin olive oil extraction yield and quality, it is clear that the available scientific data are not exhaustive, and a comprehensive understanding of all the variables affecting the length of malaxation is still far away.

\section{Dispelling some common myths}

The most common clichés on virgin olive oil extraction process: true or false? It depends on the progress in the scientific knowledge base.

It is very hard to get rid of the most common beliefs on virgin olive oil because they are consolidated in our minds. Let's look at several of them to highlight if other possible points of view are available and also if any perspectives for future researches exist.

\section{Crushing}

The integral crushing is the unique milling solution able to guarantee good extraction yields.

It is widespread assumed that de-stoning of the olive paste leads to a reduction of the oil yield to about $1.5 \mathrm{~kg}$ of oil per $100 \mathrm{~kg}$ of olives in comparison to the other processes (crushing by means stone mill and mechanical crushers) (Amirante et al., 2006; Amirante et al., 2010a) and that this reduction is due to absence of pit fragments which contribute to friction and cutting effect on cells, thus facilitating oil release. Due to this ascertainment, the employment of the de-stoner as milling crushing system is not widespread in oil mills despite other relevant advantages:

- De-stoned paste is solely made up of the fleshy part of the olive (mesocarp), without the stone (endocarp) that holds the seed and most of the oxidative enzymes. The resulting virgin olive oil has a higher phenol content than those obtained by other crushing systems (Amirante et al., 2006; Servili et al., 2007; Clodoveo et al., 2014).

- Considering that the stones constitute about $25 \%$ of the total paste volume, the use of the de-stoner can improve the working capacity of the mill plant excluding about a quarter of the residual solid waste before the extraction process (Clodoveo et al., 2014).

- The seeds, rich in functional and bioactive minor compound (often lost into the wastes), after the recovering, have a high economic appeal because of their residual value for the cosmetic and pharmaceutical industries (Amirante et al., 2010a).

Additionally, the de-stoned pomace is easier to use as an animal feed (Brozzoli et al., 2010; Ragni et al., 2011; Servili et al., 2011).

On the contrary the olive pit presence offers other undoubted disadvantages:

The presence of olive pit reduces the work capacity of the whole mill plant.

The reduction of the size of pits during the crushing requires a large dissipation of mechanical energy and its conversion into thermal energy warms the olive paste before of the thermolabile enzymes triggering such as lipoxygenase (LOX) and hydroperoxide lyase (HPL).

During the olive paste warming the olive pit fragments, which constitute a by-product, absorb thermal energy with the burden of a heavy economic cost and a not sustainable process.

If the pit fragments are too small, rather than facilitate the oil drain, can produce opposite effects, causing the clogging of the decanter and reducing the extraction yields.

The problem of the minor oil yield due to the employment of the destoner has been overcome by recent innovations:

A company leader in the production of machinery for the olive oil industry, Alfa Laval, has introduced in the market a new product named EVOOline (Figure 4). It is a tubular heat exchanger that incorporates corrugated tubes designed to increase turbulence in the flow of the olive paste to be warming. This apparatus, collocated

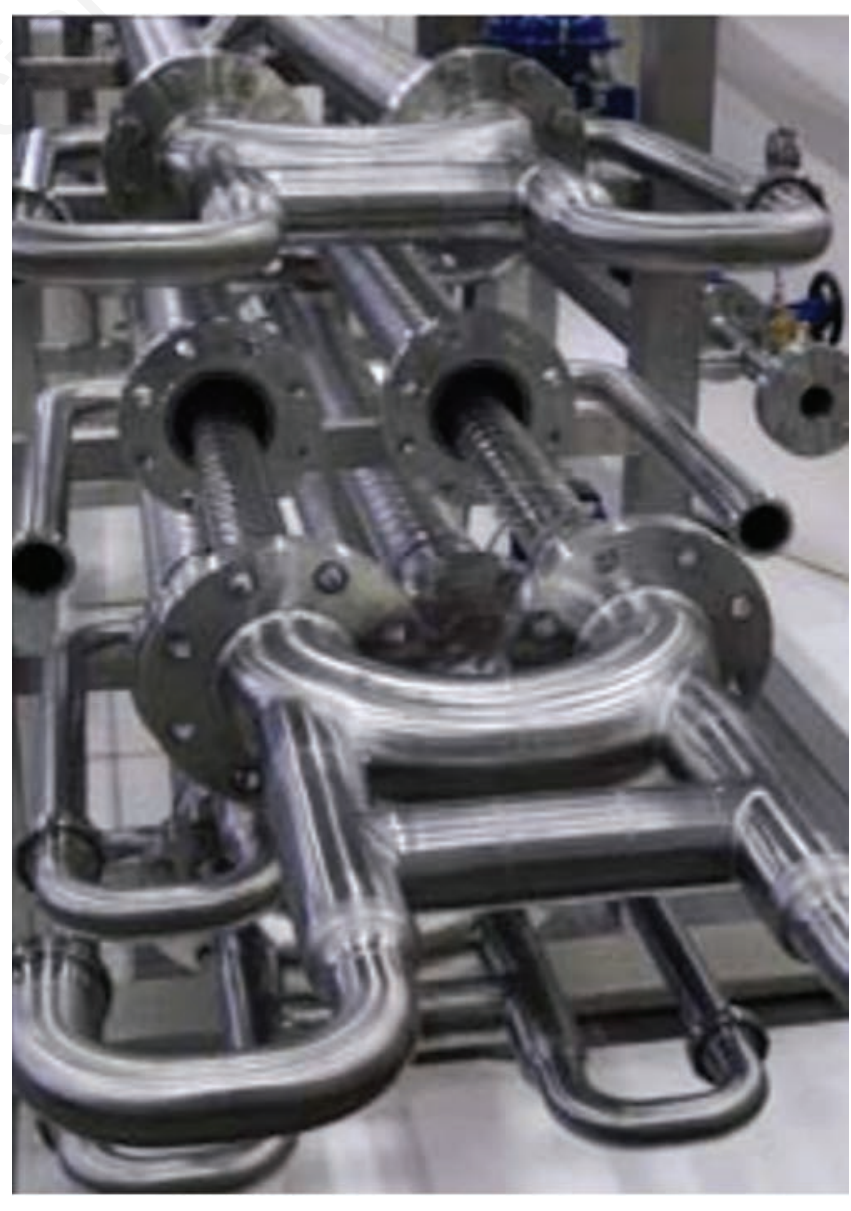

Figure 4. Tubular heat exchanger designed to warm the olive paste (Courtesy of Alfa Laval Olive Oil S.p.A.). 
between the crusher and the malaxer, reduces significantly the length of the process (about 40\% less). Preliminary results obtained on de-stoned olive paste of Peranzana cultivar reveled a significative increment of oil yields on average equal to $1 \mathrm{~kg}$ of oil per $100 \mathrm{~kg}$ of olives.

- Also the ultrasound treatment of the de-stoned olive paste gave similar results. The mechanical effect of cavitation, breaking of the cell walls after few seconds of treatment, substitutes the friction and cutting effect of the pit fragments on cells, thus facilitating the oil release.

\section{Malaxation}

A low (20-30 rpm) and continuous kneading of olive paste for 30-45 min is needful to help the small droplets of the oil formed during the milling to merge into large drops (coalescence phenomena) that can be easily separated through mechanical systems.

In order to dispel this myth and improve the knowledge on the fluid dynamics of the separation process of oil from olive paste, it is convenient to have a better understanding of the mechanism of coalescence. The coalescence phenomena of oily drops inside the olive paste are due to the hydrophobic interactions. During the malaxation, the drops of oil into the olive paste combine to form a larger drop (Amirante R. et al., 2001; Clodoveo, 2012). This comes about because the water molecules in the olive paste are attracted to each other and are cohesive because they are polar molecules. Oil molecules are non-polar and thus have no charged regions on them. This means that they are neither repelled nor attracted to each other. The attractiveness of the water molecules for each other then has the effect of squeezing the oil drops together to form a larger drop (Nosonovsky and Bhushan, 2008) (Figure 5A).

The hydrophobic effect is largely due to the special ability of water molecules to form hydrogen bonds (H-bonds) with themselves, attempting to avoid structural arrangements where the network of these H-bonds is perturbed. Non-polar molecules such as lipids thus tend to aggregate, so minimising their surface contact, and the associated surface energy, with water (Dias et al., 2010). The role of the mixing in the hydrophobic interaction regards frequency of the collision of drops, which is one of the factors able to influence the coalescence of the oil in the olive paste. Mixing or agitation has been shown to augment coalescence by enhancing the rate of collisions (Sjoblom, 2001). Also, the role of the temperature in the hydrophobic interaction is well known; in fact, experimental observations reveals that if the olive paste is warmed the coalescence phenomena increase (Esposto et al., 2013) confirming that the hydrophobic effect increases with increasing temperature (Pánek et al., 2011). This phenomenon is easily explained as the hydrophobic effect is part of a family of processes called entropy driven ordering. The hydrophobic effect seeks to minimize the free energy of the system by minimizing the interface surface between hydrophobic molecules and water (Figure $5 \mathrm{~B}$ ). This reaction is spontaneous because is characterized by a negative value of the Gibb's energy. The Gibb's energy is described by the following equation:

$$
\Delta \mathrm{G}=\Delta \mathrm{H}-\mathrm{T} \Delta \mathrm{S}
$$

where $\Delta \mathrm{G}$ is the change in free energy $\left(\mathrm{J} \mathrm{mol}^{-1}\right), \Delta \mathrm{H}$ is the change in enthalpy $\left(\mathrm{J} \mathrm{mol}^{-1}\right), \Delta \mathrm{S}$ is the change in entropy $\left(\mathrm{J} \mathrm{K}^{-1} \mathrm{~mol}^{-1}\right)$ and $\mathrm{T}$ is the value of temperature $(\mathrm{K})$.

In presence of the hydrophobic molecules, water molecules have to make new hydrogen bonds and form an ice-like cage structure called a clathrate cage around the oily drop. This orientation makes the system more structured with and characterized by a low entropy. When hydrophobic molecules stick together, they minimize the area exposed to water and, as consequence, entropy increases because of the num- ber of water molecules which compose the clathrate cage decreases. The entropy-driven interactions are intrinsically temperature sensitive. When temperature increases, entropy also increases, the Gibb's energy become more negative, and, as consequence, hydrophobic effect occurs easier.

An increase in temperature promotes oil/water separation because has also the following effects:

- Reduces the viscosity of the oil.

- Increases the mobility of the water droplets.

- Increases droplet collisions and favours coalescence.

- Increases the difference in densities of the fluids.

At this point of the discussion, is legitimate to ask: are mixing and temperature the unique parameters useful to increase the coalescence phenomena? Are available other technological solution untested yet?

A viable alternative could be achieved trying to implement the already known technique. In fact, the newest malaxer machines are hermetic sealed in order to ensure a perfect control of the atmosphere in contact with the olive paste through valves for inert gas treating (nitrogen or argon), reducing the negative effects caused by a pro-

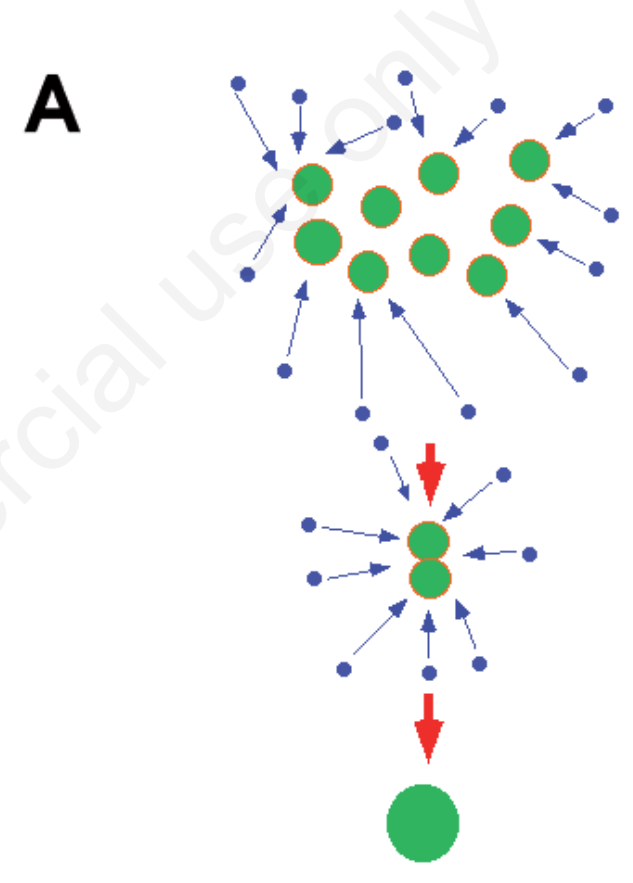

B
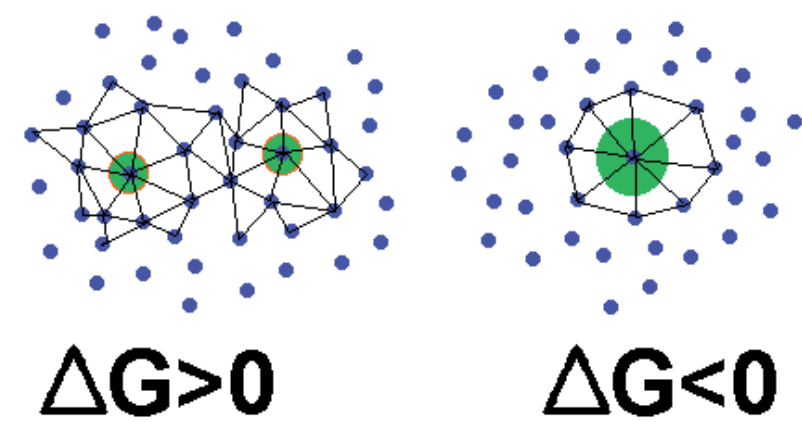

$\square$ water $\square$ oil

Figure 5. The hydrophobic effect. 
longed contact of paste with oxygen, mainly when olive cultivars poor in polyphenols are extracted. These valves are usually implemented on the top of the vessel (Clodoveo, 2012; Clodoveo, 2013a, 2013b; Clodoveo, 2014). A simple dislocation of this device on the bottom of the tank could favour the coalescence in analogy with the adsorptive bubble separation processes. Adsorptive bubble separation process has many significant industrial applications, also oil-water separation (Rosenthal $e t$ $a l ., 1996)$. This is a complex physico-chemical process used widely in the food processing industry to separate particles in a mixture on the basis of their surface chemistry, specifically their hydrophobicity. The particles are suspended in a fluid and gas bubbles are introduced. The separation of a binary mixture is due to the selective attachment of hydrophobic particles to gas bubbles. The particles that are hydrophobic or non-wetting will attach to the bubbles and rise to the top of the containing vessel to form a layer on the surface of the fluid mass due to the difference in the density between the air bubbles and hydrophilic fluid, that provides buoyancy that preferentially lifts the hydrophobic particles to the surface effecting the separation (Wang et al., 2010). Some gases (such as $\mathrm{N}_{2}$ and $\mathrm{Ar}$ ), even with their low solubility, may accumulate at hydrophobic surfaces favouring the hydrophobic effect, whereas others, for example $\mathrm{CO}_{2}$, contrast the coalescence phenomena.

In the recent years the use of the ultrasound conditioning in adsorptive bubble separation process has been expanding due to the evidence that this technology increase the efficiency of the hydrophobic particles separation. Jordan (1991) has demonstrated that ultrasound positively affects collision and attachment of particles to bubbles and bubble coalescence. Filippov et al. (2013) confirmed clearly that ultrasound treatment could activate the separation of the slow fraction, that part of hydrophobic particles that are characterised by a low speed. The increased kinetics can be explained hypothesising that the ultrasound cavitation can modify the surface of hydrophobic particles by micro or nano bubbles formation and facilitate the bubble-particle attachment. Cavitation bubbles occur mainly on hydrophobic surfaces. Therefore, oil drops could be activated by the cavitation. The ultrasound influence on particles collision probability could lead to an increase of oil recovery but this hypothesis needs a direct experimental confirmation if applied to the olive paste.

In a recent paper published on the Journal of Agricultural Engineering, Toschi et al. (2014) analysed the effect of a vibration systems on the oil yield suggesting an application of this system to the olive paste aimed to improve the malaxation phase. The mechanical vibrations can allow the breaking of the cells and facilitate the next operations without relevant and critical thermal effects. In this experimentation sinusoidal vibration tests was conducted in the $5-200 \mathrm{~Hz}$ frequency range on olive paste after hammer crushing. The main effect of vibration is to increase the number of collision between hydrophobic particles. A significant increase in the extraction yield was observed in the vibrated olive pastes. Both resonant excitation frequency and duration can significantly affect the oil extraction. However, the resonant conditions experimentally founded were surely related to the physicalmechanical characteristics of the tested olive pastes and can be affected by several factors such as the cultivar, the maturity stage of the olives and the milling process. What emerged with certainty is that the extractive effectiveness occurred at a precise frequency and, in this sense, it will be necessary to set, from time to time the frequency of excitation more favourable for maximum extraction of the oil. Further studies can be carried out in order to assess if the combination of the vibration with the malaxation can positively influence the quality of the virgin oil produced and the energy balance of the process, by reducing the time of the whole malaxation phase.

In general, a comprehensive understanding of all the variables affecting coalescence of oil into the olive paste requires further researches but it opens up new and interesting industrial applications.
The discontinuity of malaxation derives from the fact that the transformations taking place in this operation are rate limited and cannot be effectively carried out into short time.

Actually, the malaxation requires two-thirds of the time needed for the whole extraction process, from milling step to separation phase of the oil (Clodoveo 2012, 2013a, 2013b, 2014). The virgin olive oil plant manufacturers are interested to the search for new continuous extraction processes, which can increase the yield reducing the producing cost of the resulting product (Clodoveo, 2013c). In fact, a continuous process presents potential advantages such as minor operating costs, minor capacity limitations, faster return on investments, lower cost of production, reduced energy demands, reduced work-in-progress, faster and easier cleaning, real-time quality control and significantly reduced footprint facility (Clodoveo et al., 2013a).

Malaxation of olive paste must be considered much more than a simple physical separation, because a complex bioprocess takes place that is very relevant to the quality and composition of the final product. During malaxation considerable changes in the oil's chemical composition occur because of the partition phenomena between oil and water and vice versa and the catalytic activity of fruit enzymes, which are released during the crushing step, owing to disruption of the cell tissues (Clodoveo, 2012).

While trying to understand the physic-chemical, chemical and biochemical transformations occurring during malaxation, two main questions need to be answered. Which are the critical parameters to control the diffusion and equilibrium phenomena between the aqueous and the oil phases? Which is the time needed to trigger enzymatic activity and to produce the pleasant volatiles which characterise virgin olive oil?

Most of the relevant enzymatic reactions, both desirable and undesirable, occur in the presence of oxygen. In particular, the most desirable one regards the synthesis of volatile compounds thought the lipoxygenase pathway (Clodoveo et al., 2014). Lipoxygenase enzymatic pathway combines the actions of three enzymes: lipase, LOX and HPL converting lipidic substrates, such as $\mathrm{C18}: 2$ and C18:3 fatty acids, into short chain volatiles. These reactions, triggered by cell membrane disruptions, produce compounds known as green leaf volatiles, which are C6 or C9-aldehydes and alcohols (Crouzet, 1997). The lipoxygenases, after their release owing to cellular disruption of fruits, immediately become active and transform the unsaturated fatty acids, linolenic and

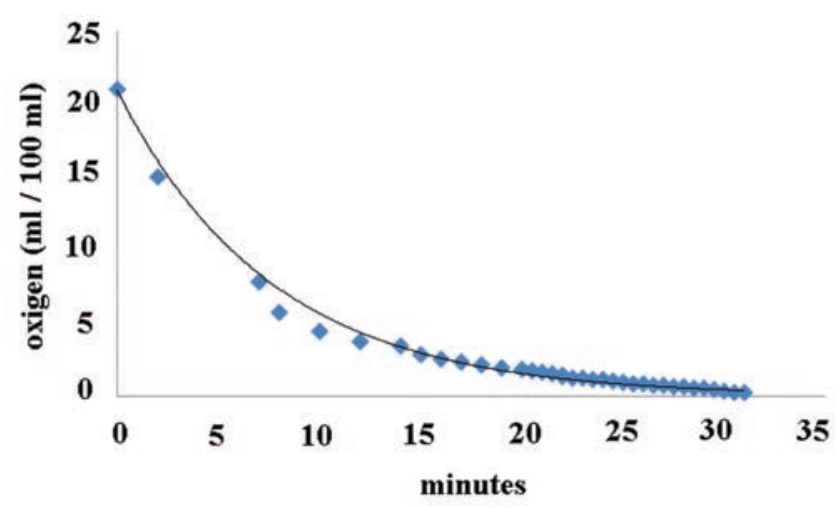

Figure 6. Depletion of $\mathrm{O}_{2}$ measured inside the olive paste during malaxation. 
linoleic acids, into $\mathrm{C} 6$ and $\mathrm{C} 5$ compounds that contribute to green odor notes (Angerosa et al., 2001 Sanchez-Ortiz et al., 2012, Clodoveo, 2012). These observations were confirmed by Amirante et al. (2012b) that measured the concentration of $\mathrm{O}_{2}$ inside the olive paste in an hermetic malaxer: the initial concentration of oxygen was equal to $18 \%$. This value was halved after $5 \mathrm{~min}$ and becomes equal to $5 \%$ after $10 \mathrm{~min}$ (Figure 6).

The graphic relative to the emission of $\mathrm{CO}_{2}$ (Figure 7) reveals that in the early $8 \mathrm{~min}$ a negligible concentration of this gas was detected.

After this period, a rapid increase in concentration was observed followed by a gradual decrease in emission rate. The depletion of oxygen in the early minutes can be ascribable to enzymatic reactions that are not associated to the production of carbon dioxide (Clodoveo et al., 2014). After this initial period, the effects of cellular respiration became prevalent and the $\mathrm{CO}_{2}$ saturated the head space of the malaxer, depriving the lipoxygenase pathway of oxygen, thereby inhibiting the synthesis of other volatile compounds. However, more exhaustive researches on the kinetics of the various endogenous enzymes immediately after the crushing are needed in order to better elucidate how many time are effectively required to obtain the desirable products synthesis. In a recent paper, Clodoveo et al. (2014) provided a sound scientific basis and a systematic analysis of the main olive enzymatic activities involved in the complex biotransformation that occurs during the mechanical extraction process. They also provided a critical and interpretative discussion of the influence of each step of the extraction process on the polyphenols and the volatile compounds analysing the effect of the different mechanical devices that are part of the elaboration process on the virgin olive oil yield and quality.

Along with the synthesis of new compounds, absent in the olive fruit but present in the final oil, it is important to clarify if and how they can be transferred from the aqueous phase of olive paste (the medium in which chemical and biochemical reactions occur) to the oily phase. Different types of chemical species can be transferred between the several systems present in olive-oil mills and the oil in elaboration (Gómez Herrera, 2007). When the olive cells are crushed, a very extensive interfacial area between aqueous and oily phases is created. Through this area high potentiality factors exist able to favour the transfer of chemical species of the paste into the oil since their initial concentration in this oil is zero. It should be taken into account that the magnitude of any transfer is a function of the chemical nature of the transferred species. However, the transfer rate can be increase favouring the movement of the oil droplets among the other systems of the olive paste and the continuous renewal of the interfacial exchange regions. At the same time, the other side of the coin has to be evaluated: the movement of the oil droplets increase the number of efficient collisions enhancing the coalescence phenomena. This involves a gradual and considerable reduction in the total interfacial area initially existent between the oil droplets and the rest of the paste. The rate of this reduction will influence the concentration of minor components in the oil at the end of its elaboration. As regard to polyphenols, a detailed analysis on their partition phenomena between aqueous and oily phases, and the relative law, is described by Clodoveo (2012). For the nonglyceridic components (chlorophylls, xanthophylls and carotenes), the concentration in the resulting virgin olive oil can be increased applying any available techniques able to break up the epicarp cells, such as ultrasound, microwave and pulsed electric field, emerging technologies used widely in the food processing industry. This is well illustrated in the following paragraphs.

Low temperatures $\left(\leq 30^{\circ} \mathrm{C}\right)$ are always recommended for the malaxation step so that a satisfactory yield and a good quality of oil can be achieved.

From a physical point of view, higher temperature increases the oil yield because it reduces the oil viscosity and promotes the aggregation of the oil droplets (Inarejos-García et al., 2009). In early research study, Ranalli et al. (2001) suggested a kneading temperature not higher than $30^{\circ} \mathrm{C}$ as they found a general deterioration of the oil quality at $35^{\circ} \mathrm{C}$, without any substantial increase of the extraction yield. Furthermore, Kalua and coworkers (Kalua et al., 2006) showed that a temperature increase up to $45^{\circ} \mathrm{C}$ resulted in a significant lowering of the yield. This data are not surprising, but coherent and well explained by Amirante P. et al. (2001). Figure 8 shows that the curves of extraction yield as a function of malaxing time, for three different malaxing temperatures $\left(27,32\right.$ and $\left.35^{\circ} \mathrm{C}\right)$, had a parabolic shape. Amirante, by means these results, effectively demonstrated that during malaxation a time/temperature relationship exists.

Each parabolic curve presents the maximum value at different times: the higher temperature $\left(35^{\circ} \mathrm{C}\right)$ allows to reach the higher oil yield after $30 \mathrm{~min}$; at $32^{\circ}$ and $27^{\circ} \mathrm{C}$ the maximum yields are reached after 45 an $60 \mathrm{~min}$ respectively. The inverse relationship between temperature and time during malaxation can be an useful tool to reduce the length of the process, also considering that the newest malaxers allow to protect the oil against oxidation by means the use of inert gas and, at the same time, the loss of aromas due to the increase of vapour pressure of the volatile compounds is inhibited by the hermetic closure. What can be observed about the olive oil quality obtained at high temperature? Recently, Esposto et al. (2013) tested the introduction of a heat

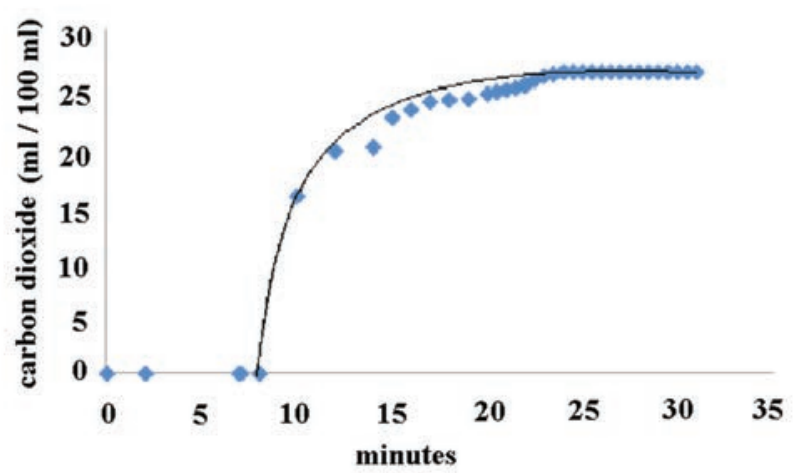

Figure 7. Development of $\mathrm{CO}_{2}$ measured inside the olive paste during malaxation.

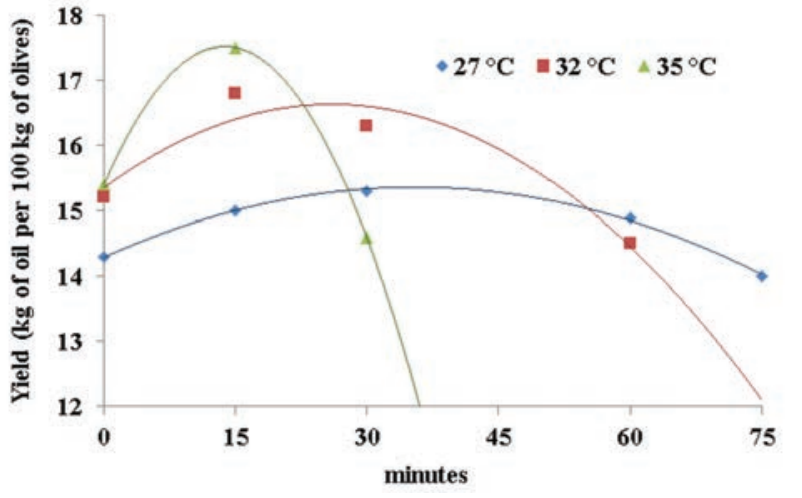

Figure 8. Time/temperature relationship and the effects on virgin olive oil yields. 
exchanger before malaxation because the traditional malaxation process has low thermal transfer efficiency, and for this reason, the thermal conditioning of olive pastes is relatively long compared to the optimal processing temperature. They found that optimal operative conditions (time and temperature) applied during malaxation after the flash thermal conditioning treatment of the olive paste can be opportunely chosen for improving the relative virgin olive oil quality. Moreover, Fiori et al. (2014) tested a preheating treatment of the olive paste (combined or not with malaxation) in order to replace malaxation under certain conditions of time and temperature. They monitored the quality of the virgin olive oil at the extraction stage and during 12 months of storage. They observed that a fast preheating not longer than $72 \mathrm{~s}$ at $38^{\circ} \mathrm{C}$ without malaxation lead to an extra virgin olive oil with a shelf-life of at least 12-months, similarly to the traditional virgin olive oil obtained with malaxation. A fast preheating not longer than $72 \mathrm{~s}$ at $38^{\circ} \mathrm{C}$ followed by 10 min malaxation lead to an virgin olive oil with a mild sensory profile and a shelf life of at least 12-months. Thus, the use of a specific designed fast preheater instead or before (a shortened) malaxation allows to obtain a virgin olive oil with a low bitter/pungent attribute; in fact they observed that the phenolic content decreased in the oil when fast preheating was followed by malaxation.

The presence of oxygen in the headspace of the malaxer strongly affects polyphenols and volatile compounds, prompting the use of a controlled and modified atmosphere during the malaxation process.

The influence of the presence of oxygen in the headspace of the malaxer has been deeply studied, while, a poorly studied aspect concerns the influence of the atmosphere composition in contact with the olive paste during the crushing. Considering that the measure of the oxygen concentration inside the olive paste after crushing revealed an average value of $18 \%$ (very similar to the atmosphere composition) (Amirante et al., 2012), it is important to develop innovative crushing systems able to modulate atmosphere composition inside the crushing chamber in order to obtain a strategic control the oxygen concentration into the olive paste and to prevent undesirable oxidative reactions, mainly catalysed by POD and P00, in the subsequent malaxing step where the process parameters are favourable for these enzymatic activities. An example of a plant that allows to modulate the atmosphere composition from the crusher to the malaxer has been described in a recent patent (Clodoveo, 2013c), property of the University of Bari.

The equipment comprises a section for inletting olives into the washing machine (Figure 9A). Olives are then carried to the bottom of the vat. A device keeps the olives on the bottom and sends them to the conveyor belt (Figure 9B) feeding the crusher (Figure 9D). The atmosphere upstream of the crusher is balanced by the hydrostatic pressure of the water vat, whereas downstream of the crusher it is delimited by the hermetic closure of the malaxer. The atmosphere composition can be modulated both in the crusher and in the kneader by means a valve implemented on the malaxer (Figure 9F).

A feasible solution could be represented by the possibility to crush the olive under inert gas and subsequently to inject oxygen in the olive paste monitoring the evolution of volatile compounds (Servili et al., 2008) by means an e-nose sensor (Esposto et al., 2009).

An American company which produces machinery for the olive oil industry has introduced in the market a new product named ApolloCulitvar 500. It is a small-size extraction plant that operates under vacuum. The producer built this equipment in order to dramatically reducing the olive paste exposure to oxygen by operating under vacuum, and obtaining a product richer in polyphenols. However, this new equipment has not been ever validated by a scientific research. Probably a weakness of this device could be the loss of aromas due to the low vapor pressure of the volatile compounds.

The few data that are available in the international literature on this topic demonstrates that there is an important scientific lacuna on the control of atmosphere composition inside the crusher. Future researches may well clarify the relevance of this plant implementation, but in any case, the atmosphere control limited to the malaxer machine is ineffectual because of the high rate of enzymatic reactions that are activated during crushing could make useless any modulation attempts.

\section{Future trends: the application of emerging technologies in virgin olive oil elaboration process}

The use of emerging technologies is spreading widely in many food sectors. Emerging technologies are new food technologies, which respond to the needs of our epoch: sustainable processes and foods with improved nutrition al value. A brief sketch of the state of the art of the emerging technologies, such as ultrasound, microwave and pulsed electric fields, in virgin olive oil elaboration process can be given as follows.

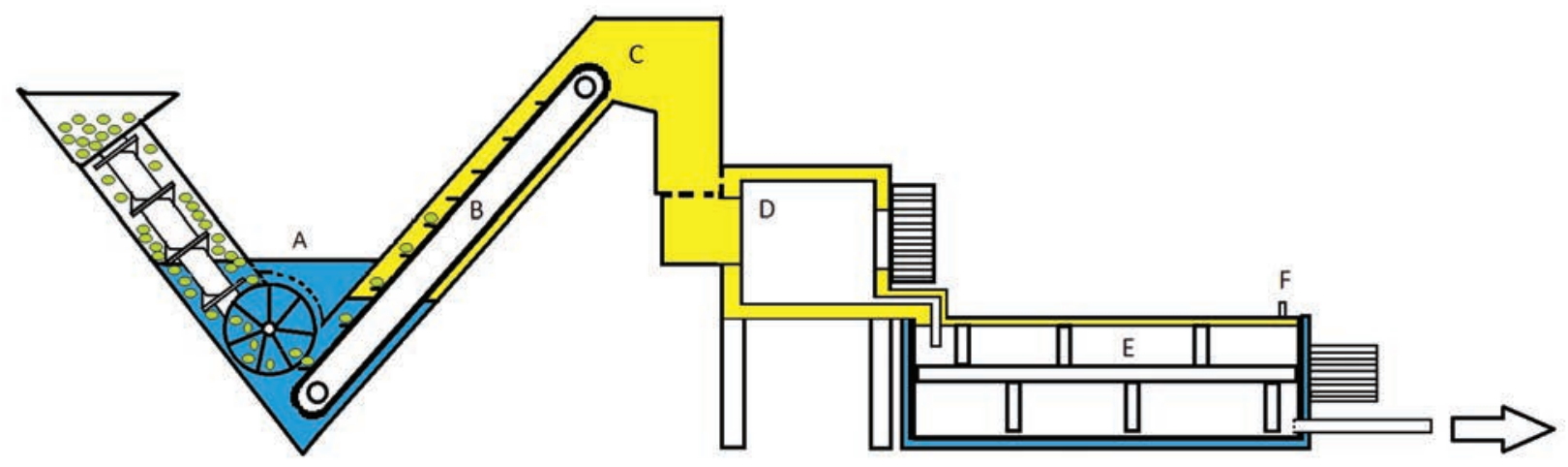

Figure 9. Method and apparatus for thermal conditioning of olives or other oleaginous fruits combined with a crushing and kneading system of olives or other oleaginous fruits in controlled or modified atmosphere (Patent No. 2013076592). 


\section{Applications of pulsed electric field technology in virgin olive oil elaboration process}

Pulsed electric field treatment involves the application of short pulses of high voltage in order to disrupt biological cells in the food material. Depending on the treatment intensity (electric field strength, number and duration of the electric pulses) and cell properties (size, shape, orientation, conductivity) the pore formation may be permanent or temporary (Figure 10) (Zimmermann et al., 1974; Zimmermann et al., 1976; Angersbach et al., 2000).

Cell membrane acts as a physical barrier in removing the intracellular substances (water, oil, and antioxidants) from plant tissues in solidliquid extraction (Puértolas et al., 2015). The disintegration or permeabilisation of the cell membrane olive fruit can allow the release of intracellular water, oil and solutes (secondary metabolites) to migrate in an external medium (Ade-Omowaye et al., 2001). Although the pulsed electric field treatment is defined as a non-thermal food processing technology, there is a significant temperature increase during high intensity pulsed electric field treatment due to Joule heating (Sastry and Barach, 2000). The increase in product temperature is function of the energy input (Toepfl et al., 2006) and in comparison to conventional thermal processing is quite low and in general do not affect the functional and nutritional value (e.g. vitamin content) of the food in contrast to traditional heating methods (Olsen et al., 2010). Abenoza et al. (2012) studied the effect of the application of pulsed electric field of different intensities $(0-2 \mathrm{kV} / \mathrm{cm})$ on Arbequina olive paste coupled with different malaxation times $(0,15$, and $30 \mathrm{~min})$ and temperatures $\left(15\right.$ and $26^{\circ} \mathrm{C}$ ). They observed that when the olive paste was treated with pulsed electric field $(2 \mathrm{kV} / \mathrm{cm})$ without malaxation the extraction yield improved by $54 \%$. At $15^{\circ} \mathrm{C}$, a pulsed electric field treatment of $2 \mathrm{kV} / \mathrm{cm}$ improved the extraction yield by $14.1 \%$, which corresponded with an enhancement of $1.7 \mathrm{~kg}$ of oil per $100 \mathrm{~kg}$ of olive fruits. Therefore, they suggested the application of this emerging technology could permit a reduction of the malaxation temperature from 26 to $15^{\circ} \mathrm{C}$ without damaging the extraction yield. These data confirm that therefore, the treatment of the olive paste with pulsed electric field has the potential to induce cell disintegration and to facilitate the release of the small oil droplets.

\section{Applications of ultrasound technology in virgin olive oil elabora- tion process}

Ultrasound is a form of energy generated by sound waves of frequencies above $16 \mathrm{kHz}$ (Jayasooriya et al., 2004). Two main mechanisms of ultrasound are useful to optimise the virgin olive oil elaboration

\section{ELECTRIC FIELD}
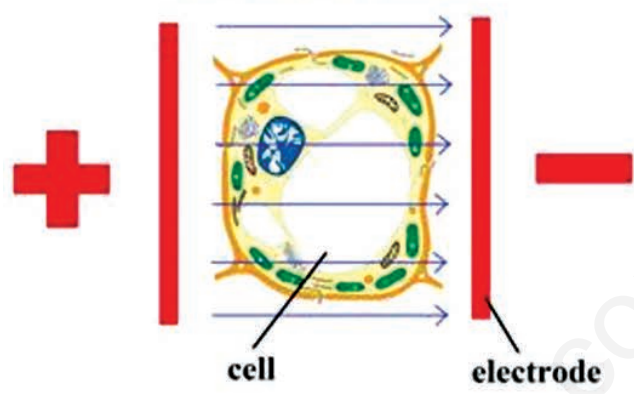
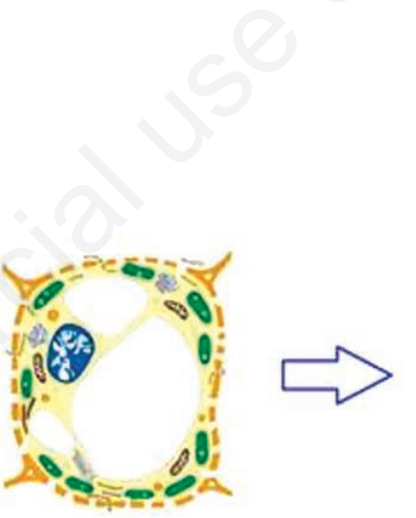

Cell membrane

permeabilisation

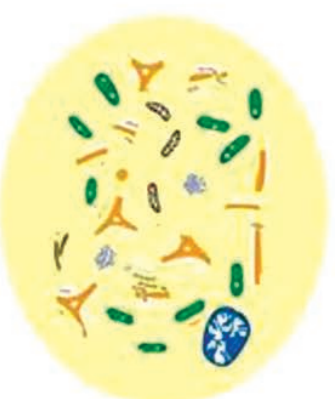

Distruction of cell membrane

Figure 10. Effect of electric field on cell membrane: membrane permeabilization.
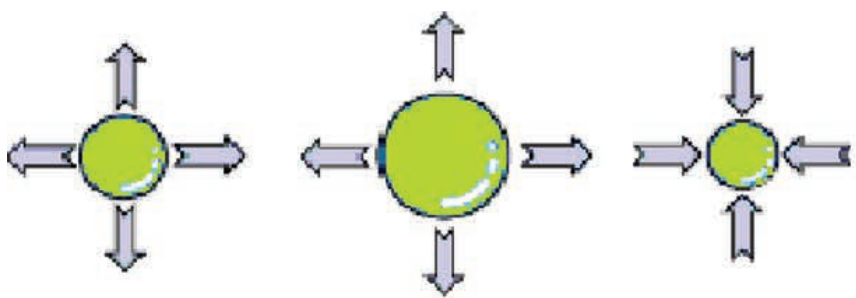

Cavitation buble

Maximum bubble size growth in negative pressure
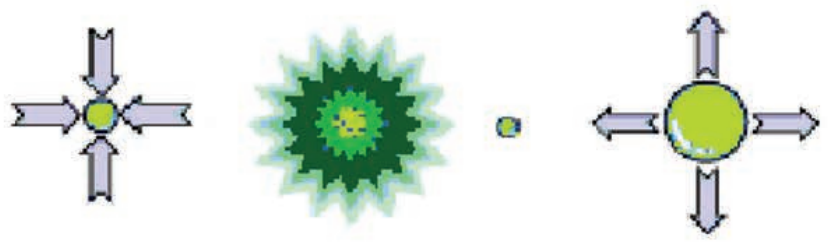

Bubble collapse

in compression
$\mathrm{C}$

Cycle repeats New bubble growth

Figure 11. Cavitation phenomena. 
process: the mechanical and the thermal effects (Clodoveo et al., 2013). Mechanical action is due to the cavitation phenomena (Luque Garcìa and Luque de Castro, 2003), which disrupt the biological cell walls (Cravotto et al., 2008). Heating occurs as the ultrasonic energy is absorbed in a medium (Jayasooriya et al., 2004; Zheng and Sun, 2006). Cavitation can be defined as the formation, growth and subsequent collapse of vapor and/or gas-vapor filled bubbles in the liquid (Zhou et al., 2009) (Figure 11).

The implosion of cavitation bubbles generates macro-turbulence, high-velocity inter-particle collisions and perturbation in micro-porous particles of the biomass, which accelerates the diffusion of cellular content (Vilkhu et al., 2008, 2011). The thermal effect occurs as kinetic energy from the ultrasound waves is absorbed by a medium ( $\mathrm{Wu}$ and Nyborg, 2008). In order to reduce the malaxing time enhancing the quality of the product, Clodoveo et al. (2013a, 2013b) tested an ultrasound assisted virgin olive oil extraction processes against the traditional method. When the ultrasound treatment to the olive paste (cv. Coratina) was applied instead the conventional heating system (Clodoveo et al., 2013b; Clodoveo and Hbaieb, 2013), a quick heating of the product occurs. Applying the conventional heating method of the olive paste, the length of the pre-heating stage was about $45 \%$ of the total process time, taking 25 min to carry the olive paste up $30^{\circ} \mathrm{C}$ before the effective malaxation stage. Applying the ultrasound treatment (35 $\mathrm{kHz}-150 \mathrm{~W})$ on the olive paste $(2.5 \mathrm{~kg})$ the pre-heating length was about 10 min (Clodoveo et al., 2013a, 2013b), corresponding to a 60\% reduction in respect to the conventional system. Parameters legally established (acidity, peroxide value, $\mathrm{K}_{232}$, and $\mathrm{K}_{270}$ ) to measure the level of quality of the virgin olive oil were not affected by the ultrasound treatments. The application of ultrasound treatment did not generate any bad flavour or taste in the oil and improved antioxidant content in the resulting oil. Ultrasound well responds to the needs of our epoch: it is a sustainable process and improves the nutrition al value of the resulting oil.

\section{Applications of microwave technology in virgin olive oil elaboration process}

Microwaves are non-ionising electromagnetic waves of frequency between $300 \mathrm{MHz}$ to $300 \mathrm{GHz}$ (Banik, 2003). It is a technology applied in many food processes to reduce heating processing times (Mullin, 1995). Microwave technology presents also a mechanical effect due to the heating, which determines an increasing of the vegetal tissue volume and, in this way, cells explode releasing their content into the liquid phase. Moreover, when the liquid phase absorbs the microwave, the kinetic energy of its molecules increases, and consequently, the diffusion rate increases too (Kratchanova et al., 2004; Mandal et al., 2007). Considering the thermal and mechanical effects of this emerging technology, experimental trials were carried out in a pilot scale plant applying microwave treatments on olive paste. When the microwave treatment was performed a reduction of $88 \%$ of the conventional pre-heating time was obtained. Microwaves didn't affect the legal parameters in the tested experimental conditions (temperature treatment: $30^{\circ} \mathrm{C}$ ). The oils obtained by applying the microwave treatment on olive paste were more pigmented than the conventional ones. This result confirms that the microwaves cause the increase of vegetal tissue volume disrupting the cells and releasing the pigments. Considering the effect of microwave treatment on extraction yields, employing the pilot scale plant, the extraction yield was $16.7 \%( \pm 0.2)$, and $17.1 \%( \pm 0.1)$ for the conventional and microwave treatment respectively.

A deeper and critical analysis of the process scalability and the energetic and economic aspects of the emerging technologies is reported by Clodoveo (2013b). The results relative to the employment of emerging technologies in virgin olive oil process appears promising, there are still, however, considerable knowledge gaps that will need to be addressed, and possible regulatory hurdles to be overcome, before commercialisation of the industrial plants.

\section{Conclusions}

Considering how many question are still unanswered, the actual knowledge about the effects of virgin olive oil elaboration process on virgin olive oil quality is like the visible portion of an iceberg. A comprehensive understanding of all the variables affecting the complex series of physical, physico-chemical, chemical and biochemical transformations is still far away and represents the invisible portion of the iceberg. The application of new emerging technologies, such as pulsed electric field, ultrasound and microwave, in the virgin olive oil elaboration process offers a number of advantages due to their mechanical and thermal effects. In contrast with the existing technology, the considered merging ones are able to cause the rupture of cell walls and recovering the oil and minor compounds trapped in the uncrushed olive tissue, increasing the work capacity of the extraction plant and reducing the process time. However, the potential application of any new technologies, which are coming from research laboratories and not sanctioned by centuries of empirical use (Farkas, 2001), can be influenced by many factors: i) technological feasibility; ii) technical possibility; iii) health impact (wholesomeness of the product and occupational safety); iv) environmental friendliness; v) economic feasibility (including their energy demand); vi) infrastructural conditions/requirements; vii) investment need and availability of investment power; viii) political attitude; ix) social consequences; $x$ ) psychological aspects/risk-benefit perception.

Whereas the first four aspects listed can be scientifically studied, and clear-cut general answers can be given according to the status of science and technology of a given epoch, the other factors are very much interrelated and depend on specific conditions. From the food industry side, there is a need to metabolise the novelty of the aforementioned technologies to appreciate their potential over the hurdles that must be overcome.

\section{References}

Abenoza M., Benito M., Saldaña G., Álvarez I., Raso J., Sánchez-Gimeno A.C. 2012. Effects of pulsed electric field on yield extraction and quality of olive oil. Food Bioproc. Technol. 6:1-7.

Ade-0mowaye B.I.O., Angersbach A., Taiwo K.A., Knorr D. 2001. Use of pulsed electric field pre-treatment to improve dehydration characteristics of plant based foods. Trends Food Sci. Technol.12:285-95.

Amirante P., Clodoveo M.L., Dugo G., Leone A., Tamborrino A. 2006. Advance technology in virgin olive oil production from traditional and de-stoned pastes: Influence of the introduction of A, heat exchanger on oil quality. Food Chem. 98:797-805.

Amirante P., Clodoveo M.L., Tamborrino A, Leone A. 2012a. A new designer malaxer to improve thermal exchange enhancing virgin olive oil quality. Acta Hortic. 949:455-62.

Amirante P., Clodoveo M.L., Tamborrino A., Leone A., Dugo G. 2008. Oxygen concentration control during olive oil extraction process: a new system to emphasize the organoleptic and healthy properties of virgin olive oil. Acta Hortic. 949:473-80.

Amirante P., Clodoveo M.L., Tamborrino A., Leone A., Dugo G. 2012b. Oxygen concentration control during olive oil extraction process: a new system to emphasize the organoleptic and healthy properties 
of virgin olive oil. Acta Hortic. 949:473-80.

Amirante P., Clodoveo M.L., Tamborrino A., Leone A., Paice A. 2010a. Influence of the crushing system: phenol content in virgin olive oil produced from whole and de-stoned pastes olives and olive oil in health and disease prevention. Academic Press Ltd., Elsevier Science Ltd, London, UK, pp 69-76.

Amirante P., Clodoveo M.L., Tamborrino A., Leone A., Patel V. 2010b. Influence of different centrifugal extraction systems on antioxidant content and stability of virgin olive oil olives and olive oil in health and disease prevention. Academic Press Ltd., Elsevier Science Ltd, London, UK, pp 85-93.

Amirante P., Pasqualone A., Clodoveo M.L., Montel G.L., Catalano P., Cini E., Cresti G. 2001. Influenza delle tecniche estrattive sulla qualità dell'olio in Toscana. Atti del Convegno di Studi "Nuovi sistemi di coltivazione dell'olivo. Aspetti agronomici, economici e qualitativi”, Firenze, Italy, pp 63-67.

Amirante R., Catalano P. 2000. PH - Postharvest technology: fluid dynamic analysis of the solid-liquid separation process by centrifugation. J. Agric. Engine. Res. 77:193-201.

Amirante R., Cini E., Montel G.L., Pasqualone A. 2001. Influence of mixing and extraction parameters on virgin olive oil quality. Grasas Aceites 52:198-201.

Angerosa F., Basti C. 2001. Olive oil volatile compounds from the lipoxygenase pathway in relation to fruit ripeness. Ital. J. Food Sci. 13:421-8.

Angersbach A., Heinz V., Knorr D. 2000. Effects of pulsed electric fields on cell membranes in real food systems. Innov. Food Sci. Emerg. Technol. 1:135-49.

Banik S., Bandyopadhyay S., Ganguly, S. 2003. Bioeffects of microwave - a brief review. Bioresour. Technol. 87:155-9.

Brozzoli V., Bartocci S., Terramoccia S., Contò G., Federici F., D'Annibale A., Petruccioli M. 2010. Stoned olive pomace fermentation with "Pleurotus" species and its evaluation as a possible animal feed. Enzyme Microb. Technol. 46:223-8.

Clodoveo M.L. 2012. Malaxation: Influence on virgin olive oil quality. Past, present and future - an overview. Trends Food Sci. Technol. 25:13-23.

Clodoveo M.L. 2013a. An overview of emerging techniques in virgin olive oil extraction process: Strategies in the development of innovative plants. J. Agric. Engine. 44:297-305.

Clodoveo M.L. 2013b. New advances in the development of innovative virgin olive oil extraction plants: Looking back to see the future. Food Res. Int. 54:726-9.

Clodoveo M.L. 2013c. WIPO Patent No. 2013076592. World Intellectual Property Organization, Geneva, Switzerland.

Clodoveo M.L., Durante V., La Notte D. 2013a. Working towards the development of innovative ultrasound equipment for the extraction of virgin olive oil. Ultrasonic. Sonochem. 20:1261-70.

Clodoveo M.L., Durante V., La Notte D., Punzi R., Gambacorta G. 2013b. Ultrasound assisted extraction of virgin olive oil to improve the process efficiency. Eur. J. Lipid Sci. Technol. 115:1062-9.

Clodoveo M.L., Hbaieb R.H. 2013. Beyond the traditional virgin olive oil extraction systems: searching innovative and sustainable plant engineering solutions. Food Res. Int. 54:1926-33.

Clodoveo M.L., Hbaieb R.H., Kotti F., Mugnozza G.S., Gargouri M. 2014. Mechanical strategies to increase nutritional and sensory quality of virgin olive oil by modulating the endogenous enzyme activities. Comprehensive Rev. Food Sci. Food Safety. 13:135-54.

Cravotto G., Boffa L., Mantegna S., Perego P., Avogadro M., Cintas, P. 2008. Improved extraction of vegetable oils under high-intensity ultrasound and/or microwaves. Ultrasonic. Sonochem. 15:898-902.

Crouzet J. 1997. Flavor biogeneration. In functionality of food phytochemicals. Springer, New York, NY, USA, pp 179-200.
Dias C.L., Ala-Nissila T., Wong-ekkabut J., Vattulainen I., Grant M., Karttunen M. 2010. The hydrophobic effect and its role in cold denaturation. Cryobiology 60:91-9.

Esposto S., Montedoro G., Roberto M., Taticchi A., Urbani S., Servili M. 2009. Monitoring of virgin olive oil volatile compounds evolution during olive malaxation by an array of metal oxide sensors. Food Chem. 113:345-50.

Esposto S., Veneziani G., Taticchi A., Selvaggini R., Urbani S, Di Maio I., Sordini B., Minnocci A., Sebastiani L., Servili M. 2013. Flash thermal conditioning of olive pastes during the olive oil mechanical extraction process: Impact on the structural modifications of pastes and oil quality. J. Agric. Food Chem. 61:4953-60.

Farkas J. 2001. Future trends in food technology - novel food and transgenic food - a review. Acta Alimentaria 30:267-79.

Filippov L.O., Matinin A.S., Samiguin V.D., Filippova I.V. 2013. Effect of ultrasound on flotation kinetics in the reactor-separator. J. Physics Conf. Ser. 416:012016.

Fiori F., Di Lecce G., Boselli E., Pieralisi G., Frega N.G. 2014. Effects of olive paste fast preheating on the quality of extra virgin olive oil during storage. Food Sci. Technol. 58:511-8.

Gómez Herrera C. 2007. Matter transfer during virgin olive oil elaboration. Grasas Aceites 58:194-205.

Inarejos-García A.M., Gómez-Rico A., Salvador M.D., Fregapane G. 2009. Influence of malaxation conditions on virgin olive oil yield, overall quality and composition. Eur. Food Res. Technol. 228:671-7.

Jayasooriya S.D., Bhandari B.R., Torley P., D'Arcy B.R. 2004. Effect of high power ultrasound waves on properties of meat: a review. Int. J. Food Properties 7:301-19.

Jordan C.E. 1991. U.S. Patent No. 5,059,309. U.S. Patent and Trademark Office, Washington, DC, USA.

Kalua C.M., Bedgood D.R., Bishop A.G., Prenzler P.D. 2006. Changes in volatile and phenolic compounds with malaxation time and temperature during virgin olive oil production. J Agric. Food Chem. 54:7641-51.

Kratchanova M., Pavlova E., Panchev I. 2004. The effect of microwave heating of fresh orange peels on the fruit tissue and quality of extracted pectin. Carbohydrate Polymers 56:181-5.

Luque Garcìa J.L., Luque de Castro M.D. 2003. Ultrasound: a powerful tool for leaching TRAC. Trends Analyt. Chem. 22:41-7.

Mandal V., Mohan Y., Hemalatha S. 2007. Microwave assisted extraction - an innovative and promising extraction tool for medicinal plant research. Pharmacognosy Rev. 1:7-18.

Mullin J. 1995. Microwave processing. In: G.W. Gould (Ed.), New methods of food preservation. Springer, New York, NY, USA, pp 112-134.

Nosonovsky M., Bhushan B. 2008. Underwater superhydrophobicity and dynamic effects. multiscale dissipative mechanisms and hierarchical surfaces: friction, superhydrophobicity, and biomimetics. Springer, New York, NY, USA, pp 169-178.

Olsen N.V., Grunert K.G., Sonne A.M. 2010. Consumer acceptance of high-pressure processing and pulsed-electric field: a review. Trends Food Sci. Technol. 21:464-72.

Parenti A., Spugnoli P., Masella P., Calamai L., Pantani O.L. 2006. Improving olive oil quality using $\mathrm{CO} 2$ evolved from olive pastes during processing. Eur. J. Lipid Sci. Technol.108;904-12.

Pánek J., Filippov S.K., Koňák Č., Nallet F., Noirez L., Karlsson G., Št pánek P. 2011. Polymeric nanoparticles stabilized by surfactants investigated by light scattering, small-angle neutron scattering, and cryo-TEM methods. J. Dispersion Sci. Technol. 32:888-97.

Puértolas E., de Marañón I.M. 2015. Olive oil pilot-production assisted by pulsed electric field: impact on extraction yield, chemical parameters and sensory properties. Food Chem. 15:497-502.

Ragni M., Melodia L., Bozzo F., Colonna M.A., Megna V., Toteda F., Vicenti A. 2011. Use of a de-stoned olive pomace in feed for heavy 
lamb production. Ital. J. Animal Sci. 2:485-7.

Ranalli A., Contento S., Schiavone C., Simone N. 2001. Malaxing temperature affects volatile and phenol composition as well as other analytical features of virgin olive oil. Eur. J. Lipid Sci. Technol. 103:228-38.

Rosenthal A., Pyle D.L., Niranjan K. 1996. Aqueous and enzymatic processes for edible oil extraction. Enzyme Microbial Technol. 19:402-20.

Sanchez-Ortiz A., Romero-Segura C., Sanz C., Perez A.G. 2012. Synthesis of volatile compounds of virgin olive oil is limited by the lipoxygenase activity load during the oil extraction process. J. Agric. Food Chem. 60:812-22.

Sastry S.K., Barach J.T. 2000. Ohmic and inductive heating. J. Food Sci. 65:42-46.

Servili M., Esposto S., Taticchi A., Urbani S., Selvaggini R., Di Maio I., Veneziani G. 2011. Innovation in extraction technology for improved virgin olive oil quality and by-product valorisation. Acta Hortic. 888:303-16.

Servili M., Taticchi A., Esposto S., Urbani S., Selvaggini R., Montedoro G. 2008. Influence of the decrease in oxygen during malaxation of olive paste on the composition of volatiles and phenolic compounds in virgin olive oil. J. Agric. Food Chem. 56:10048-55.

Sjoblom J. (ed.). 2001. Encyclopedic handbook of emulsion technology. CRC Press, Boca Raton, FL, USA.

Toepfl S., Heinz V., Knorr D. 2006. Applications of pulsed electric fields technology for the food industry. In: J. Raso and V. Heinz (Eds.), Pulsed electric fields technology for the food industry. Springer, New York, NY, USA, pp 197-221.
Toschi T.G., Berardinelli A., Cevoli C., Iaccheri E., Di Lecce G., Bendini A., Ragni L. 2014. Effectiveness of the mechanical excitation applied to the olive paste: possible improving of the oil yield, in malaxation phase, by vibration systems. J. Agric. Engine. 44:166-9.

Vilkhu K., Manasseh R., Mawson R., Ashokkumar M. 2011. Ultrasonic recovery and modification of food ingredients. In: H. Feng, G. Barbosa-Canovas, J. Weiss (Eds.), Ultrasound technologies for food and bioprocessing. Springer, New York, NY, USA, pp 345-368.

Vilkhu K., Mawson R., Simons L., Bates D. 2008. Applications and opportunities for ultrasound assisted extraction in the food industry - A review. Innov. Food Sci. Emerg. Technol. 9:161-9.

Wang L.K., Shammas N.K., Selke W.A., Aulenbach D.B. 2010. Gas dissolution, release, and bubble formation in flotation systems. In: L.K. Wang, N.K. Shammas, W.A. Selke, D.B. Aulenbach (Eds.), Flotation technology. Springer, New York, NY, USA, pp 49-83.

Wu J., Nyborg W.L. 2008. Ultrasound, cavitation bubbles and their interaction with cells. Adv. Drug Deliv. Rev. 60:1103-16.

Zheng L., Sun D.-W. 2006. Innovative applications of power ultrasound during food freezing processes - a review. Trends Food Sci. Technol. 17:16-23.

Zhou Z.A., Xu Z., Finch J.A., Masliyah J.H., Chow R.S. 2009. On the role of cavitation in particle collection in flotation - A critical review. II. Minerals Engine. 22:419-33.

Zimmermann U., Pilwat G., Beckers F., Riemann F. 1976. Effects of external electrical fields on cell membranes. Bioelectrochem. Bioenerg. 3:58-83.

Zimmermann U., Pilwat G., Riemann F. 1974. Dielectric breakdown in cell membranes. Biophys. J. 14:881-99. 